\title{
Oxidative stability of crude extract of red variety rice bran from Minahasa, North Sulawesi on lipid-based food products
}

\author{
${ }^{1}$ Moko, E.M., ${ }^{1}$ Ngangi, J. and ${ }^{2 *}$ Rahardiyan, D. \\ ${ }^{1}$ Biology Department, Mathematics and Natural Sciences Faculty, Manado State University, Tondano, \\ 95619 Indonesia \\ ${ }^{2}$ Agribusiness Department, Faculty of Agricultural, De La Salle Catholic University, Manado, 95000, \\ Indonesia
}

\begin{abstract}
Article history:
Received: 20 October 2018 Received in revised form: 4 December 2018

Accepted: 12 January 2019 Available Online: 23 January 2019
\end{abstract}

\section{Keywords:}

Antioxidant,

Food products,

North Sulawesi,

Red variety rice bran,

Oxidative stability

DOI:

https://doi.org/10.26656/fr.2017.3(3).236

\begin{abstract}
Rice bran is known to contain various phytochemical compounds, particularly, vitamin E in the form of tocopherol and tocotrienol that has antioxidant potential. The purpose of this research was to understand the antioxidant capabilities of the crude extract of red variety rice bran from North Sulawesi to inhibit the oxidation process in fortified mayonnaise. Fortified mayonnaise samples with fish oil were incorporated with red variety rice bran (RRB) extract and butylated hydroxy toluene (BHT). Butylated hydroxy toluene (BHT) was used as a synthetic antioxidant for comparison. The mayonnaise samples were stored for a period of 30 days and observed for the inhibition of oxidation characteristics. Observations were performed at day 0,10,20 and 30 of the storage. Among the analysis conducted during the observations were the formation of conjugated-diene-hydroperoxide, the detection of malonaldehyde (MDA) via TBARS method and the hydroperoxide formation via FTIR chromatogram. The results indicated that the mayonnaise with RRB extract $(21.55 \pm 0.80 \mathrm{mmol} / \mathrm{kg})$ had a higher inhibition of oxidation at the primary stages of storage compared to mayonnaise with BHT $(21.84 \pm 1.48 \mathrm{mmol} / \mathrm{kg})$ from the observation in the formation of conjugated-diene-hydroperoxide. While the formation of MDA of mayonnaise with BHT was less $(0.23 \pm 0.01 \mathrm{mg} / \mathrm{kg})$ compared to mayonnaise with RRB extract $(0.24 \pm 0.03 \mathrm{mg} / \mathrm{kg})$. The FTIR chromatogram results indicated that the control sample and pure fish oil had peaks beyond $3500 \mathrm{~cm}^{-1}\left(3649 \mathrm{~cm}^{-1}, 3673 \mathrm{~cm}^{-1}, 3748 \mathrm{~cm}^{-1}\right.$ and $3838 \mathrm{~cm}^{-1}$ ) after 30 days of storage.
\end{abstract}

\section{Introduction}

Rice bran is one of the by-products of the rice milling process that contains various phytochemicals and natural antioxidants including phenol compounds (Chatha et al., 2006; Srisawat et al., 2010). Rice bran oil contains about 0.1-0.14 vitamin E components such as tocopherols and tocotrienols and about $0.9-2.9 \%$ oryzanol (Thanonkaew et al., 2006). Rice bran oil is 95.6\% saponified lipid as in glycolipids and phospholipids also about $4.2 \%$ unsaponified lipid-like tocopherols, tocotrienols, $\gamma$-oryzanol, sterols and carotenoids (Xu and Godber, 1999; Chen et al., 2008). Parrado et al. (2006), indicated that fatty acid components of rice bran oil are dominated by oleic acid (up to $42.4 \%$ ) and linoleic acid (36.4\%), thus rice bran oil is categorized as unsaturated fatty acid.

Food products are known as products with a limited lifespan (shelf life), thus very susceptible to damage.
One of the most fragile of food products is lipid-based food products. The lipid oxidation process is one of the most influencing factors of lipid degradation, which is initiated by heat and airborne contact thus causing food spoilage which is indicated by color and odor changes.

Rice bran oil is known to have the antioxidant activities and can be used as an alternative to replace chemical derived antioxidant such as BHT (Butylated Hydroxy Toluene) and BHA (Butylated Hydroxy Anisole). Researches that were conducted previously on the use of rice bran oil as a substitute of fortification antioxidant were regarding the effects of red rice extracts in fish oil fortified mayonnaise towards its oxidative stability during shelf life (Tananuwong and Tewaruth, 2010). Previous research conducted by Moko et al. (2014) on the antioxidant characteristics of several varieties of North Sulawesi rice. It was indicated that crude extract of the red variety of rice bran had better antioxidant characteristics compared to other varieties 
(Cigeulis and Superwin) which was shown by the DPPH scavenging radical activity of $88.29 \pm 5.62 \%$ with the lowest $\mathrm{IC}_{50}$ value $(26.26 \pm 0.95 \mu \mathrm{g} / \mathrm{ml})$ and highest total anthocyanin content $(68.61 \pm 1.98 \mathrm{mg} / \mathrm{g})$. The purpose of this research was to understand the oxidative stability of the crude extract red variety rice bran oil of North Sulawesi, especially on its antioxidative activities in oxidation inhibition process in lipid-based food products.

\section{Materials and methods}

The main attention of this research is focused on rice bran as the main material, which in this case was red variety rice bran from North Sulawesi cultivated in the Minahasa regencies were used. Materials used in the extraction were blue ice, organic solvents and pro analysis ethanol. While the required materials for the conduct of this research were fish oil (from Lansida, Yogyakarta), vegetable oil (commercial soy oil), egg yolk, vinegar, mustard, potassium sorbate, table salt, synthetic antioxidant BHT, isooctane, butanol and thiobarbituric acid reagent (TBA).

\subsection{Sample preparation}

RRB were obtained freshly from the rice mills of the Parepei Village, Remboken Munciple, Minahasa Regency, North Sulawesi, Indonesia. RRB was stabilized according to a method of Malekian et al. (2000) by autoclaving at $120^{\circ} \mathrm{C}$ for 3 mins to inactivate the lipase enzymes within the rice bran, followed by cooling of the samples at room temperature for one night.

\subsection{Sample extraction}

The extraction of the RRB was performed according to the methods of $\mathrm{Hu}$ et al. (1996) and Iqbal et al. (2005). The antioxidant extraction of the RRB was conducted using organic solvents (ethanol PA). The samples were macerated with ethanol for $72 \mathrm{hrs}$ where all the RRB samples were completely marinated and submerged in the solvent. The end of this process was marked by the change in color whereby the mixture became brighter. The mixture was then separated using the Whatman paper No. 40, and solvents were evaporated using a rotary vacuum evaporator at $50^{\circ} \mathrm{C}$ to obtain the RRB extract.

\subsection{Fish oil fortified mayonnaise}

Mayonnaise fortified with fish oil was used as the applicative test subject. Samples were made according to the work of Tananuwong and Tewaruth (2010) with slight modification with the following ingredients: $78.9 \mathrm{~g}$ oil (vegetable oil and fish oil in a ratio of $3: 1), 9.5 \mathrm{~g}$ vinegar, $8.9 \mathrm{~g}$ egg yolk, $1.3 \mathrm{~g}$ table salt, $1.0 \mathrm{~g}$ potassium sorbate and $0.7 \mathrm{~g}$ mustard. RRB crude extract (as the natural antioxidant) and synthetic antioxidant BHT was weighed $1000 \mathrm{mg}$ and diluted in vinegar before mixing in with the other ingredients accordingly. All the materials are then blended together in a mixer at high speed until a consistent emulsion was achieved.

The mayonnaise produced were then packed in sealed plastic packages and incubated at $30^{\circ} \mathrm{C}$ for 30 days, and further testing on oxidative stability and color changes were carried out. Testing were done on day 0 , 10, 20 and 30 of the storage. Each sample was made in triplicate where each packaged sample was used only once for each test at the respective period of storage testing.

\subsection{Oxidative stability testing}

Oxidative stability testing was only done on the oil phase of the mayonnaise. Mayonnaise samples were centrifuged at $25.400 \times \mathrm{g}\left(4^{\circ} \mathrm{C}\right)$ for 10 mins to obtain the oil phase. The samples were then tested for conjugated diene hydroperoxide, TBARs and hydroperoxide formation by FTIR. The tests were also performed on the fish oil used in the production of the mayonnaise to verify that the rancidity was not caused by the fish oil itself.

\subsubsection{Conjugated diene hydroperoxides}

The testing for conjugated diene hydroperoxides was conducted following the method of Frankel et al. (1994). A total of $50 \mathrm{mg}$ of the oil phase of the mayonnaise samples were added with $5 \mathrm{~mL}$ isooctane. Absorbances of the dilution was read at $234 \mathrm{~nm}$ using a spectrophotometer. Conjugated diene hydroperoxides concentration was then calculated based on the Lambert Beer equation with molar absorptivity of $26,000 \mathrm{l} / \mathrm{mol}$ $\mathrm{cm}$ and the end value will be noted in mmol hydroperoxide/kg oil.

\subsubsection{Thiobarbituric acid reactive substances (TBARs)}

TBARs test in this research was conducted according to Pegg (2005). A total of $50 \mathrm{mg}$ of the sample in the form of mayonnaise oil phase was diluted with butanol until the total volume achieves $25 \mathrm{~mL}$, and the dilution was vortexed until homogeneous. $5 \mathrm{~mL}$ of the dilution was then mixed with $5 \mathrm{~mL}$ of TBA solution ( $0.2 \mathrm{~g}$ TBA in $100 \mathrm{~mL}$ butanol) and incubated at $95^{\circ} \mathrm{C}$ for $2 \mathrm{hrs}$. The absorbance of the sample dilutions was read at $532 \mathrm{~nm}$.

The TBARs values $\left(\mathrm{mg}^{-1}\right)$ were expressed as an increase in absorbance due to the reaction is equivalent to $1 \mathrm{mg}$ sample per $1 \mathrm{ml}$ TBA that was calculated based on the following equation: 
TBARS $=\frac{\left[50 \times\left(A_{\text {sample }}-A_{\text {blank reagent }}\right)\right]}{m}$

Where $\mathrm{m}=$ oil sample mass $(\mathrm{mg})$

\subsubsection{Hydroperoxide testing using FTIR (Fourier Transform Infrared)}

Hydroperoxide formation in the samples and the fish oil was measured by changes in the infrared spectrum using the Bruker Tensor 37 FTIR (Fourier Transform Infrared Spectrophotometer).

\subsection{Color measurement}

Color measurement was performed with a CR-300 Chromameter, Minolta Japan. Measurement results were expressed in the notations of $\mathrm{L}^{*}, \mathrm{a}^{*}, \mathrm{~b}^{*}$ and $\mathrm{c}^{*}$ (MacDougall, 2002). The color testing was done only on the mayonnaise samples and not on the oil phase of the mayonnaise unlike the oxidative stability testing.

\section{Results and discussion}

\subsection{Oxidation inhibition characteristics by rice bran antioxidant compound}

The choice of mayonnaise as an object for this research is based on the fact that mayonnaise is a complex food product made of various ingredients such as oil, egg yolk, vinegar, and mustard where all of these ingredients will develop into a complicated food interaction in the form of an emulsion that involves air entrapment. Therefore, this food product is extremely susceptible to oxidation. Fish oil was chosen based on the fact that fish oil contained unsaturated fatty acids (Polyunsaturated Fatty Acid/PUFA) which are sensitive to oxidation.

\subsection{Conjugated diene hydroperoxides}

The results shown in Table 1 and Figure 1 exhibited the conjugated diene hydroperoxides values of the oil phase of the mayonnaise samples with the addition of RRB extract and BHT during the 30 days storage. Data expressed in Table 1 indicates that the primary oxidation occurred in the early stages of storage (Day 10) was marked by the formation of conjugated dienes from the formation of peroxides in the oil phase of mayonnaise and the fish oil itself. At day 20 of storage, the conjugated dienes value declines in both the mayonnaise samples and the fish oil itself. This indicated the process of primary oxidation inhibition by RRB extract. RRB extract could inhibit primary oxidation better than BHT. This was shown in the lower conjugated dienes value in mayonnaise with RRB extract $(21.55 \pm 0.80 \mathrm{mmol} / \mathrm{kg})$ compared to mayonnaise with BHT $(21.84 \pm 1.48 \mathrm{mmol} /$ $\mathrm{kg})$ and control $(22.70 \pm 2.95 \mathrm{mmol} / \mathrm{kg})$.

At the end of the storage period, there was a rise of conjugated dienes value in all mayonnaise samples and the fish oil. This rise was larger for mayonnaise with RRB extract $(30.00 \pm 2.20 \mathrm{mmol} / \mathrm{kg})$ compared to mayonnaise with BHT $(23.82 \pm 1.64 \mathrm{mmol} / \mathrm{kg})$. This phenomenon indicated that the inhibition activity of BHT in the samples continued to secondary oxidation, while oxidation inhibition activity of RRB extract has declined. Hence, it is recommended to increase the concentration of RRB extract in the samples for better antioxidant capability.

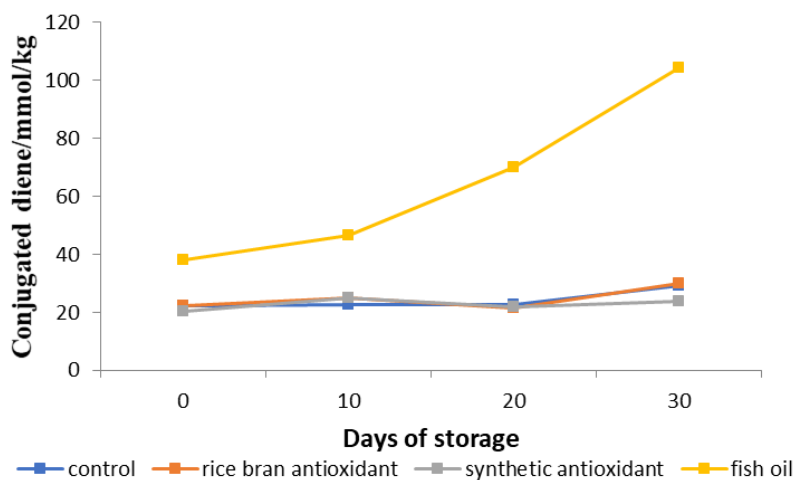

Figure 1. Conjugated diene hydroperoxide formation

The rise of conjugated dienes values in the oil phase of mayonnaise were lower than the fish oil. The rise of conjugated dienes values of fish oil was $38.26 \pm 0.86$ $\mathrm{mmol} / \mathrm{kg}$ (Day 0) to $46.62 \pm 1.39 \mathrm{mmol} / \mathrm{kg}$ (Day 10) to $69.88 \pm 2.96 \mathrm{mmol} / \mathrm{kg}$ (Day 20) and to $104.54 \pm 2.92$ $\mathrm{mmol} / \mathrm{kg}$ (Day 30). This indicated that the peroxide formation in fish oil can be related to higher oxidation process where the fatty acid molecules degraded to smaller molecules (Richardsa et al., 2005) such as aldehydes, ketones, alcohols and carboxylic acid. The rise of CDs values of the mayonnaise samples with added antioxidants were lesser than the rise in the control and this indicated that the oxidation process was more intensive in control compared to the samples added with antioxidants.

This phenomenon can also be caused by the complexity of the food ingredient interacting within the

Table 1. Conjugated diene-formation

\begin{tabular}{cccccc}
\hline & & \multicolumn{4}{c}{ Storage period (days) } \\
\cline { 3 - 6 } & & 0 & 10 & 20 & 30 \\
\hline \multirow{2}{*}{$\begin{array}{c}\text { Mayonnaise } \\
\text { Sample }\end{array}$} & Control & $22.27 \pm 0.10$ & $22.53 \pm 0.20$ & $22.70 \pm 2.95$ & $29.30 \pm 1.20$ \\
& RRB Extract & $22.12 \pm 0.28$ & $25.02 \pm 0.16$ & $21.55 \pm 0.80$ & $30.00 \pm 2.20$ \\
& BHT & $20.37 \pm 0.68$ & $24.97 \pm 1.92$ & $21.84 \pm 1.48$ & $23.82 \pm 1.64$ \\
\hline \multicolumn{2}{r}{ Fish oil } & $38.26 \pm 0.86$ & $46.62 \pm 1.39$ & $69.88 \pm 2.96$ & $104.54 \pm 2.92$ \\
\hline
\end{tabular}


emulsion system. The emulsion system will protect the oil and thus, help with the inhibition the oxidation process. The oil phase of the mayonnaise is a blend of soybean oil (vegetable oil) and fish oil which is less susceptible to oxidation compared to fish oil.

\subsection{Thiobarbituric acid reactive substances (TBARs)}

Both Table 2 and Figure 2 exhibit an increase in TBARs value in the oil phase samples of mayonnaise and the fish oil samples during the storage treatment. The formation of MDA indicated by the rise of TBARs value was observed after 20 days of storage in all samples. MDA formation occurring in all mayonnaise samples were not as high as the MDA formation of the pure fish oil itself. MDA formation in the pure fish oil at day 0 was $0.24 \pm 0.04 \mathrm{mg} / \mathrm{kg}$, increased up to $0.55 \pm 0.04$ $\mathrm{mg} / \mathrm{kg}$ at day 10 to $0.84 \pm 0.01 \mathrm{mg} / \mathrm{kg}$ at day 20 and rose to $1.32 \pm 0.03 \mathrm{mg} / \mathrm{kg}$ at day 30 .

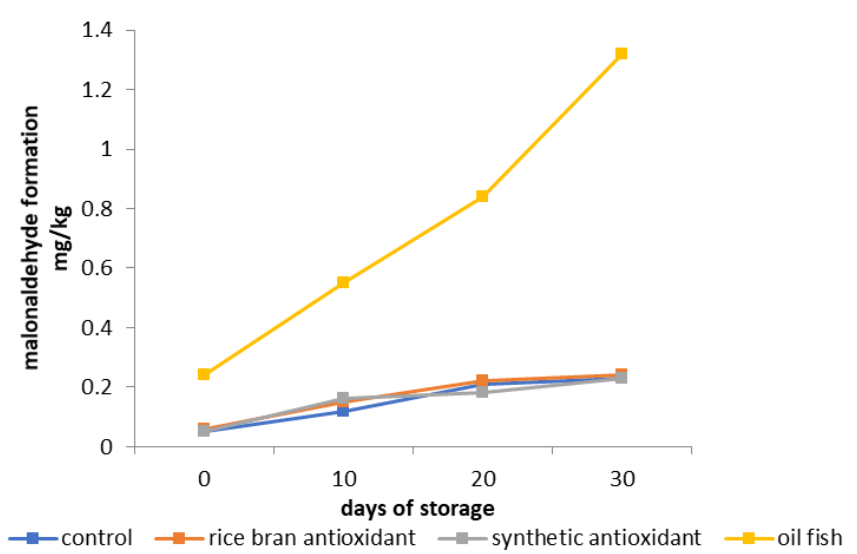

Figure 2. TBARs - MDA (Malonaldehyde Formation)

BHT had the ability to inhibit secondary oxidation, and it was better compared to RRB extract. Evidently, this was seen in the formation of MDA of mayonnaise with BHT that were smaller $(0.23 \pm 0.01 \mathrm{mg} / \mathrm{kg})$ compared to mayonnaise with RRB $(0.24 \pm 0.03 \mathrm{mg} / \mathrm{kg})$ at the end of the 30 days storage period. The data in Table 2 indicates that MDA formation that occurred in mayonnaise oil phases with antioxidants addition were smaller than the fish oil. This was probably due to the different of fatty acid composition. It was also indicated in the work of Tananuwong and Tewaruth (2010), that though the crude extract of black starchy rice could enhance the oxidative stability of mayonnaise, oxidative changes in mayonnaise could also be affected by other antioxidants presences in the food composition, producing positive synergistic effects.
3.4 Hydroperoxide formation determination by Fourier transform infrared (FTIR)

Lipid oxidation tests were also conducted by means of infrared spectrophotometry using the Fourier Transform Infra-Red (FTIR). Hydroperoxide formation as a result of the lipid oxidation process can be quantified by measuring the $\mathrm{O}-\mathrm{H}$ vibration characteristics at its absorbance with the help of infrared spectrophotometry (Shahidi and Zhong, 2010).

Table 3 exhibits that absorbances on the wave numbers of 3472-3470 $\mathrm{cm}^{-1}$ were NH groups; 3012-3009 $\mathrm{cm}^{-1}$ were $\mathrm{CH}$ groups with double bonds; $2925 \mathrm{~cm}^{-1}$ and $2854 \mathrm{~cm}^{-1}$ were $\mathrm{CH}$ groups with a single bond; $1746 \mathrm{~cm}^{-1}$ were carbonyl groups $(\mathrm{C}=\mathrm{O}) ; 1463 \mathrm{~cm}^{-1}$ were $\mathrm{C}=\mathrm{C}$ groups; and $1163-1160 \mathrm{~cm}^{-1}$ were $\mathrm{C}-\mathrm{O}$ groups. Infrared spectrums on wave numbers of $3008-3012 \mathrm{~cm}^{-1}$ indicated the presences of linoleic and linolenic acid. The presence of the two fatty acids was due to the soybean oil (vegetable oil) and the rice bran oil from the rice bran extract used in the samples. These results concurred with the work of Valantina and Neelameagam (2008) that detected infrared spectrums with wave numbers resembling rice bran oil and maize oil. Meanwhile, spectrums of wave numbers at $1651-1654 \mathrm{~cm}^{-1}$ indicates the presence of polyunsaturated fatty acids (Rohman et al., 2011) and spectrums of wave numbers at 1745-1746 $\mathrm{cm}^{-1}$ were the carbonyl groups in the long chained polyunsaturated fatty acids originated from the fish oil. Thus, the results were in agreement with the results of Ammawath and Che Man (2010), where the infrared spectrum of the carbonyl groups of triglyceride ester of sardine was detected on $1741-1746 \mathrm{~cm}^{-1}$.

The existence of $\beta$-carotenes in the mayonnaise samples and fish oil was detected on wave numbers of $2925 \mathrm{~cm}^{-1}$ and $2854 \mathrm{~cm}^{-1}$. The presence of $\beta$-carotene in palm olein was detected on wave numbers of $2922 \mathrm{~cm}^{-1}$ (Ammawath and Che Man, 2010). $\quad \beta$-carotene was also reported as a compound with antioxidative ability through its capacity in capturing free radicals or removing single oxygens (Johnson, 2001).

After 30 days of the storage period, several spectrums peaked at above $3500 \mathrm{~cm}^{-1}\left(3649 \mathrm{~cm}^{-1}, 3673\right.$ $\mathrm{cm}^{-1}, 3748 \mathrm{~cm}^{-1}$ and $3838 \mathrm{~cm}^{-1}$ respectively) were observed from the control and fish oil. Spectrum at 3800 $\mathrm{cm}^{-1}$ was detected due to some vibrations or stretching of hydroperoxides as an effect of lipid oxidation

Table 2. TBARs - MDA (malonaldehyde) formation

\begin{tabular}{|c|c|c|c|c|c|}
\hline & \multicolumn{4}{|c|}{ Storage Period (days) } \\
\hline & & 0 & 10 & 20 & 30 \\
\hline \multirow{3}{*}{$\begin{array}{c}\text { Mayonnaise } \\
\text { Sample }\end{array}$} & Control & $0.05 \pm 0.01$ & $0.12 \pm 0.03$ & $0.21 \pm 0.00$ & $0.23 \pm 0.01$ \\
\hline & RRB Extract & $0.06 \pm 0.00$ & $0.15 \pm 0.01$ & $0.22 \pm 0.01$ & $0.24 \pm 0.03$ \\
\hline & BHT & $0.05 \pm 0.00$ & $0.16 \pm 0.01$ & $0.18 \pm 0.01$ & $0.23 \pm 0.01$ \\
\hline \multicolumn{2}{|c|}{ Fish oil } & $0.24 \pm 0.04$ & $0.55 \pm 0.04$ & $0.84 \pm 0.01$ & $1.32 \pm 0.03$ \\
\hline
\end{tabular}


Table 3. Infrared spectrum of the functional groups

\begin{tabular}{ccccccc}
\hline \multirow{2}{*}{ Spectrum } & \multicolumn{7}{c}{ Functional Groups Wave Numbers $\left(\mathrm{cm}^{-1}\right)$} \\
\cline { 2 - 7 } & $\mathrm{NH}$ & $\mathrm{CH} \mathrm{sp}^{2}$ & $\mathrm{CH} \mathrm{sp}$ & $\mathrm{C}=\mathrm{O}$ & $\mathrm{C}=\mathrm{C}$ & $\mathrm{C}-\mathrm{O}$ \\
\hline 1 & 3472.6 & 3009.9 & $2926.1-2854.5$ & 1746.3 & 1463.5 & 1163.5 \\
2 & 3472.6 & 3010.0 & $2925.7-2854.4$ & 1746.2 & 1463.3 & 1163.4 \\
3 & 3472.4 & 3009.8 & $2927.5-2854.6$ & 1745.9 & 1462.4 & 1163.4 \\
4 & 3472.5 & 3009.9 & $2926.1-2854.2$ & 1745.8 & 1463.2 & 1163.3 \\
5 & 3472.5 & 3010.1 & $2925.8-2854.2$ & 1745.6 & 1462.9 & 1163.3 \\
6 & 3472.3 & 3009.9 & $2925.7-2854.3$ & 1746.1 & 1463.8 & 1163.3 \\
7 & 3472.3 & 3009.9 & $2925.9-2854.4$ & 1746.2 & 1463.5 & 1163.4 \\
8 & 3472.2 & 3010.0 & $2925.9-2854.4$ & 1746.2 & 1463.5 & 1163.3 \\
9 & 3471.3 & 30121 & $2925.4-2854.0$ & 1745.8 & 1463.4 & 1160.4 \\
10 & 3472.0 & 3010.0 & $2925.9-2854.5$ & 1746.2 & 1463.1 & 1163.2 \\
11 & 3472.4 & 3009.9 & $2925.9-2854.5$ & 1746.2 & 1463.3 & 1163.2 \\
12 & 3472.5 & 3010.0 & $2925.2-2854.5$ & 1746.1 & 1462.9 & 1163.2 \\
13 & 3470.0 & 3011.9 & $2925.5-2854.2$ & 1745.8 & 1463.1 & 1160.5 \\
\hline
\end{tabular}

Table 4. Mayonnaise color analysis during the storage study period

\begin{tabular}{clccccc}
\hline Day & Sample & $\mathrm{L}^{*}$ & $\mathrm{a}^{*}$ & $\mathrm{~b}^{*}$ & $\mathrm{C}^{*}$ & $\mathrm{~h}^{*}$ \\
\hline \multirow{3}{*}{0} & Control & $57.77 \pm 0.88$ & $2.48 \pm 0.45$ & $33.40 \pm 1.05$ & $33.47 \pm 1.08$ & $87.60 \pm 3.25$ \\
& BHT & $58.80 \pm 0.44$ & $2.99 \pm 0.47$ & $35.05 \pm 1.48$ & $35.18 \pm 1.50$ & $85.16 \pm 0.62$ \\
& RRB extract & $57.15 \pm 3.53$ & $3.24 \pm 0.11$ & $28.26 \pm 1.45$ & $28.39 \pm 1.51$ & $84.68 \pm 1.52$ \\
\hline \multirow{2}{*}{10} & Control & $49.29 \pm 6.58$ & $5.25 \pm 0.96$ & $32.03 \pm 6.20$ & $32.46 \pm 6.25$ & $80.71 \pm 0.90$ \\
& BHT & $51.61 \pm 0.41$ & $5.77 \pm 0.11$ & $43.54 \pm 0.67$ & $43.91 \pm 0.65$ & $82.50 \pm 0.20$ \\
& RRB extract & $55.87 \pm 6.33$ & $5.76 \pm 1.63$ & $32.06 \pm 7.12$ & $32.60 \pm 7.09$ & $79.63 \pm 2.91$ \\
\hline \multirow{2}{*}{20} & Control & $51.31 \pm 1.74$ & $7.76 \pm 0.55$ & $35.19 \pm 1.23$ & $36.04 \pm 1.08$ & $77.62 \pm 1.26$ \\
& BHT & $55.04 \pm 2.70$ & $6.22 \pm 0.56$ & $39.85 \pm 0.63$ & $40.32 \pm 0.68$ & $81.20 \pm 0.73$ \\
& RRB extract & $47.68 \pm 1.06$ & $4.83 \pm 0.46$ & $35.37 \pm 3.03$ & $35.70 \pm 3.07$ & $82.30 \pm 0.10$ \\
\hline \multirow{3}{*}{30} & Control & $51.35 \pm 1.39$ & $6.32 \pm 1.16$ & $41.32 \pm 3.32$ & $41.70 \pm 3.31$ & $81.28 \pm 2.25$ \\
& BHT & $49.95 \pm 3.46$ & $6.62 \pm 0.81$ & $37.42 \pm 4.21$ & $38.01 \pm 4.13$ & $81.62 \pm 1.25$ \\
& RRB extract & $48.36 \pm 2.58$ & $6.17 \pm 2.39$ & $32.50 \pm 4.38$ & $33.10 \pm 4.72$ & $77.91 \pm 0.23$ \\
\hline
\end{tabular}

(Goburdhun, 2001).

\subsection{Colour}

The color measurement results of the mayonnaise samples during the storage treatment were tabulated in Table 4 .

L* Values (Lightness) of the mayonnaise samples during 30 days of storage were shown in Figure 3. During the 30 days of storage, $\mathrm{L}^{*}$ values (lightness) of all three types of samples (control, mayonnaise with BHT, and mayonnaise with RRB extract) experienced a slight decline. The $\mathrm{L}^{*}$ values of the control mayonnaise at the beginning of the storage treatment (day 0) was $57.77 \pm 0.88$ and decreased to $51.35 \pm 1.39$ (day 30 ) while the $\mathrm{L}^{*}$ values of mayonnaise with BHT was $58.80 \pm 0.44$ (day 0 ) and decreased to $49.95 \pm 3.46$ (day 30 ). The $L^{*}$ value of mayonnaise with RRB extract was $57.15 \pm 3.53$ (day 0 ) and declined to $48.36 \pm 2.58$ (day 30 ).

In Figure 4, it is apparent that a* values (redness) of all mayonnaise samples increased during the 10 days of storage. For the control sample, the $\mathrm{a}^{*}$ value continued to increase until day 20 and began to decline at day 30. For mayonnaise with BHT, the inclination kept on going up till day 30. In contrast, mayonnaise with RRB extract exhibited a decline of $\mathrm{a}^{*}$ value at day 20 but began to increase after that as measured on day 30 . In Figure 5, the $b^{*}$ values (yellowness) of mayonnaise with BHT and RRB extract was observed during the 10 days of storage. Observations on the mayonnaise with RRB extract showed continuous increase in $\mathrm{b}^{*}$ value up to day 20 of storage but declined at day 30. Meanwhile, mayonnaise with BHT exhibited a decline after the day 10 storage. On the other hand, the controls experienced a decline in $b^{*}$ value at day 10 and then increased until the last day of storage.

The tendencies of the $\mathrm{C}^{*}$ values (Chroma/color saturation values) from all mayonnaise samples were increasing as shown in Figure 6. The $\mathrm{h}^{\mathrm{*} *}$ (hue) values of all the samples during storage treatment are exhibited in Figure 7. Figure 7 shows that the $h^{0 *}$ values of the mayonnaise samples with BHT and RRB extract decreased during the 20 days of storage and became relatively stable until 30 days of storage. A significant decrease was observed in the control samples from $84.68 \pm 1.52$ (day 0 or before storage) to $77.91 \pm 0.23$ after 30 days of storage. The sharp decrease of $h^{\circ *}$ value in the controls occurred only during the 10 days of storage, which then increased at day 20 and finally decreased again at day 30 .

The rise in degree of redness (a* values) of all 


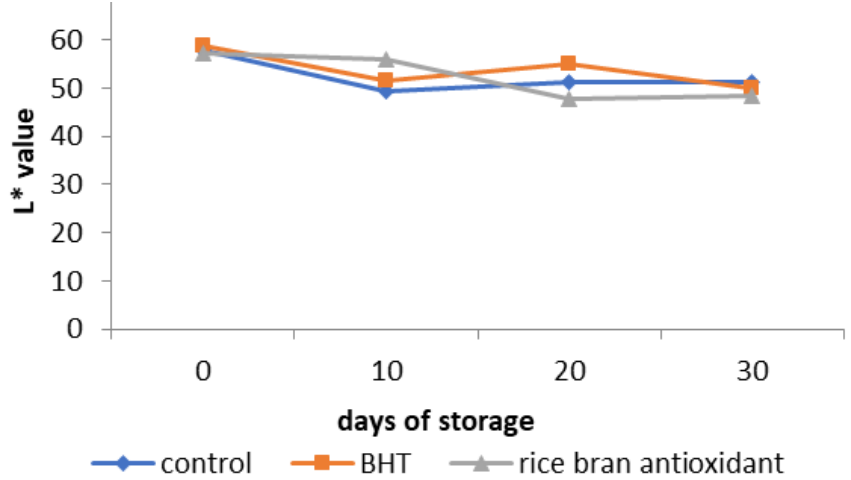

Figure 3. L* values of mayonnaise samples during the storage study period

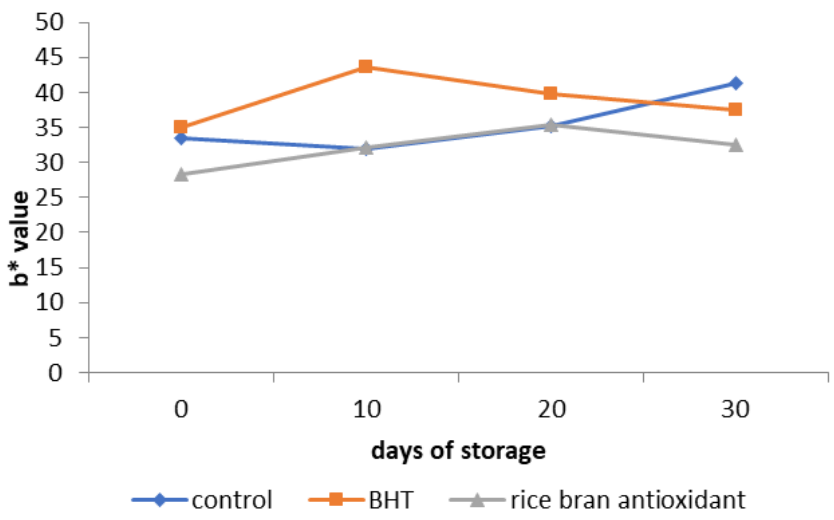

Figure $5 . b^{*}$ values of the mayonnaise samples during the storage study period

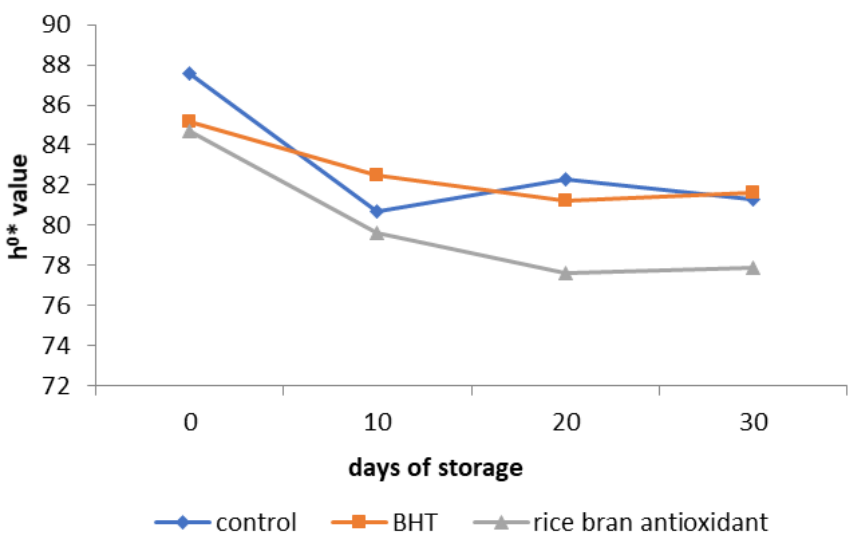

Figure $7 . \mathrm{h}^{0 *}$ values of mayonnaise samples during storage study period

samples during 30 days of storage was in accordance with the results of Tananuwong and Tewaruth (2010), which was an indication of a Maillard reaction (nonenzymatic browning reaction), a reaction of reduction sugars and the free amino acids in the egg yolks of the mayonnaise. Reineccius (2006), reported that nonenzymatic browning that occurred in a food system could be the results of a) Maillard reaction, b) lipid peroxides, c) caramelization, and d) ascorbic acid oxidation. The Maillard reaction is a non-enzymatic browning process is most common to occur. The Maillard reaction begins with an initiation reaction of carbonyl groups of the sugars with nucleophilic amino acids, although carbohydrates and sugars aren't the only sources of

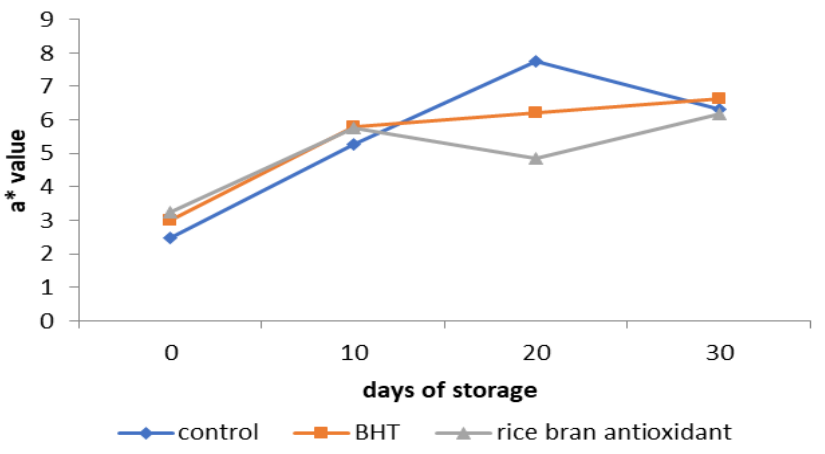

Figure 4. The a* values of mayonnaise samples during the storage study period

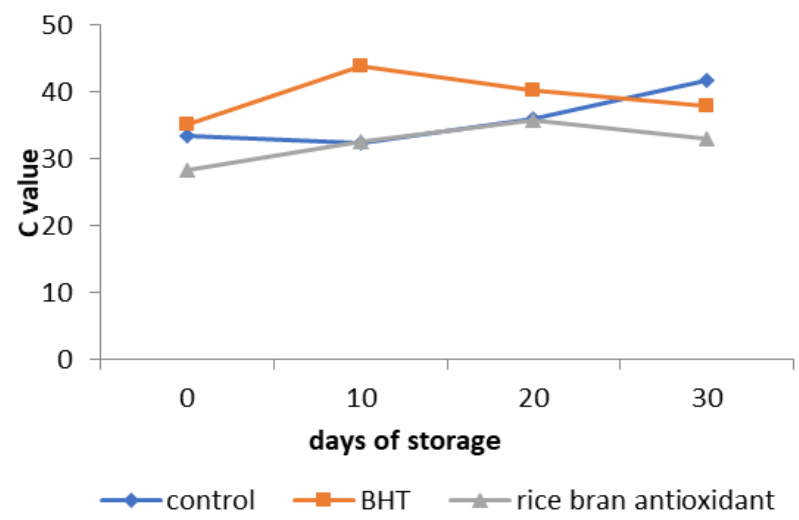

Figure $6 . \mathrm{C}^{*}$ values of mayonnaise samples during storage study period

reactive carbonyl groups in the food system. Lipid oxidation processes also produce compounds that have reactive carbonyl groups which may have a role in influencing non-enzymatic browning processes. Carbonyl groups originating from lipid sources also have the reactivity as reducing sugars by which is also reactive with the amino groups of the nucleophilic amino acids and thus may contribute to such chains of reaction (non-enzymatic browning reactions) (Zamora and Hidalgo, 2011).

Lipids and oils in this case play an important role in non-enzymatic browning reactions which is caused by the highly reactive compounds produced by the secondary lipid oxidation process, mainly of the aldehyde groups and the unsaturated carbonyl groups, in this case the malonaldehydes with the amina primer groups (Pokorny and Sakurai, 2002; Thanonkaew et al., 2006). Non-enzymatic browning mechanisms due to lipid oxidation processes begins with the formation of highly unstable hydroperoxides and further continues with the decomposition of various secondary oxidation products such as aldehydes, ketones, alchohols, epoxide and various hydrocarbon acids. These lipid oxidation products will polymerize one to the other and result in a brownish colored exopolymer (Khayat and Schwall, 1983).

These occurrences in this research were observed in 
the control that experienced an increase in the $a^{*}$ values until 20 days of storage before finally declining, unlike the mayonnaise samples with BHT and RRB extract. These mayonnaise samples have the tendency to experience non-enzymatic browning where early antioxidative compounds were developed more compared to the samples that went through later stages of non-enzymatic browning, where the carbonyl groups were already polymerized (Lu, 2013). This phenomenon was marked by the lower increases in peroxide value and the formation of malonaldehyde within the control samples in the early oxidation stages (10 days of storage) compared to formation of peroxide and malonaldehyde in mayonnaise samples with RR extract or BHT.

Color changes due to the Maillard reaction progressed slowly in low $\mathrm{pH}$ (Tananuwong and Tewaruth, 2010), in a condition where oil phase oxidation process occurred with no inhibition from the addition of antioxidant in the early stages of storage. Oxidation inhibition in the oil phase progresses as the Maillard reaction slows where the complex compounds of the end-product of the Maillard reaction with antioxidative characters begins to accumulate (Martins et al., 2001).

Free radicals of peroxides from the oil phase oxidation process in this case supports the Maillard reactions with the formations of complex polymerizations with proteins (free amino acids) from the egg yolk and continues to produce secondary lipid oxidation products such as malonaldehyde that plays their role in the formation of lipofuscins and further nonenzymatic browning reactions (Martins et al., 2001). The declining redness ( $a^{*}$ values) in the mayonnaise samples with rice bran antioxidant occurred faster after 10 days of storage, this was assumed to be conditioned where the antioxidant itself experienced oxidative degradation (Tananuwong and Tewaruth, 2010).

Suspicions on the dynamics of these $\mathrm{a}^{*}$ values in the mayonnaise samples were supported by the peroxide formation data in the primary oxidation process and the TBARs values from the secondary oxidation processes, where the $\mathrm{a}^{*}$ value increased after 20 days of storage for the mayonnaise with BHT with a lower increase of $5.77 \pm 0.11$ to $6.22 \pm 0.56$, compared to the increase of $\mathrm{a}^{*}$ values in the control from $5.25 \pm 0.95$ to $7.76 \pm 0.55$. These occurrences were in conjunction with characteristics of BHT that would inhibit oxidation processes that cause the formation of primary and secondary products that triggers the inhibition of the non-enzymatic browning reaction. This inhibition was observed in the TBARs data that was higher in the control compared to TBARs of the mayonnaise with BHT, where primary and secondary oxidation products trigger non-enzymatic browning in the control samples with forms of inhibition.

There were differences of peroxide values during the $10^{\text {th }}$ and $20^{\text {th }}$ days of storage in mayonnaise with BHT and RRB extract, in which the mayonnaise with RRB extract expressed a higher value than BHT in 10 days of storage. Mayonnaise with BHT had lower MDA values than RRB extract after 20 days of storage where this indicated that BHT had the ability to inhibit secondary lipid oxidation better than RRB extract. On the contrary, RRB extract was better at primary oxidation. This difference could be due to the substrates of these oxidation processes triggered the Maillard and other nonenzymatic browning reactions. In accordance with Hidalgo and Zamora (2000), products originating from lipid hydroperoxide decomposition or secondary products such as aldose and ketose that emerges later in the RRB extract added mayonnaise samples than BHT. Although oxidation was inhibited in mayonnaise with BHT, the inhibition process was more in the secondary process than the primary process and it occurred faster than samples with rice bran antioxidant. Thus, it was concluded that peroxide decomposition has occurred and the Maillard reaction has been initiated, although it was not as rapid as the control. Therefore, mayonnaise with BHT did not have higher a* values than the control after 20 days of storage. Secondary oxidation products first involved in the formation of lipofuscin and nonenzymatic browning were the malonaldehyde (MDA) (Hidalgo and Zamora, 2000). Thus, this supports the data of this research where the MDA values of the mayonnaise with BHT were lower than mayonnaise with RRB extract.

\section{Conclusion}

This research indicated that natural antioxidants originating from RRB have better inhibition towards the primary phase of the oxidation process, where the conjugated diene hydroperoxide formation was $21.55 \pm 0.80 \mathrm{mmol} / \mathrm{kg}$ less than the conjugated diene hydroperoxide formation of mayonnaise with BHT $(21.84 \pm 1.48 \mathrm{mmol} / \mathrm{kg}$ ). The malonaldehyde (MDA) formation in mayonnaise with BHT was relatively smaller $0.23 \pm 0.01 \mathrm{mg} / \mathrm{kg}$ compared to the MDA formation in mayonnaise with RRB $(0.24 \pm 0.03 \mathrm{mg} / \mathrm{kg})$. The FTIR results exhibited spectrums peaks above 3500 $\mathrm{cm}^{-1}\left(3649,3673,3748\right.$ and $\left.3838 \mathrm{~cm}^{-1}\right)$, because of the existence of stretching vibrations of hydroperoxides as a result of the ongoing lipid oxidation process.

\section{Acknowledgements}

A special acknowledgement is addressed to The 
Directorate of Research and Development, Ministry of Research, Technology and Higher Educations, Republic of Indonesia for the support and funding of this research.

\section{References}

Ammawath, W. and Che Man, Y.B. (2010). A rapid ethod for determination of commercial $\beta$-carotene in rbd palm olein by fourier transform infrared spectroscopy. Asian Journal of Food and AgroIndustry, 3(4), 443-452.

Chatha, S.A.S., Anwar, F., Manzoor, M. and Bajwa, J.R. (2006). Evaluation of the antioxidant activity of rice bran extracts using different antioxidant assays. Grasas Y. Aceites, 57(3), 328-335.

Chen, C.R., Wang, C.H., Wang, L.Y., Hong, Z.H., Chen, S.H. and Ho, W.J. (2008). Supercritical-carbon dioxide extractions and deadifications of rice bran oil. Journal of Supercritical Fluids, 45(3), 322-331. https://doi.org/10.1016/j.supflu.2008.01.006

Frankel, E.N., Huang, S.W., Kanner. J. and German, J.B. (1994). Interfacial phenomena in the evaluation of antioxidants: bulk oils vs emulsions. Journal of Agricultural and Food Chemistry, 42, 1054-1059. https://doi.org/10.1021/jf00041a001

Goburdhun, D., Jahumeer-Laullo, S.B. and Musruck, R. (2001). Evaluation of soybean oil quality during conventional frying by FTIR and some chemical indexes. International Journal Food Science and Nutrition, 52, 31-42. https:// doi.org/10.1080/09637480020027183

Hidalgo, F.J. and Zamora, R. (2000). The role of lipids in non-enzymatic browning. Grasas Y. Aceites, 51, 35-49. https://doi.org/10.3989/gya.2000.v51.i1-2.405

Hu, W., Wells, J.H., Shin, T.S. and Godber, J.S. (1996). Comparison of isopropanol and hexane for extraction of vitamin e and oryzanol from stabilized rice bran. Journal of the American Oil Chemists' Society, 73(12), 1653-1656. https://doi.org/10.1007/ BF02517967

Iqbal, S., Bhanger, M.I. and Anwar, F. (2005). Antioxidant properties and components of some commercially available varieties of rice bran in Pakistan. Food Chemistry, 93, 265-272. https:// doi.org/10.1016/j.foodchem.2004.09.024

Johnson, I.T. (2001). Antioxidants and Antitumor Properties. In Pokorn, J. Yanishlieva, N. and Gordon, M. Antioxidants in Food Practical Applications. Cambridge UK: Woodhead Publishing. doi.org/10.1201/9781439823057.ch6

Khayat, A. and Schwall D. (1983). Lipid oxidation in seafood. Food Technology, 37, 130-140.
Lu, H.F.S. (2013). Physico-chemical properties, oxidative stability and non-enzymatic browning in marine phospholipid emulsions and their use in food applications. Denmark: National Food Institute, Technical University of Denmark, PhD Thesis.

MacDougall, D.B. (2002). Colour Measurement of Food: Principles and Practice. In MacDougall, D.B. (Ed). Colour in Food: Improving Quality. Boca Raton: CRC Press.

Malekian, F., Rao, R.M., Prinyawiwatkul, W., Marshall, W.E., Windhauser, M. and Ahmedna, M. (2000). Lipase and lipoxygenase activity, functionally and nutrient losses in rice bran during storage. Bulletin no. 870. Baton Rounge: LSU Agricultural Center, Louisiana Agricultural Experiment Station.

Martins, S.I.F.S., Jongen, W.M.F. and van Boekel, M.A.J.S. (2001). A review of maillard reaction in food and implications to kinetic modeling. Trends in Food Science and Technology, 11, 364-373. https:// doi.org/10.1016/S0924-2244(01)00022-X

Moko E.M., Purnomo H. and Kusnadi J. (2014). Phytochemical content and antioxidant properties of colored and non colored varieties of rice bran from Minahasa, North Sulawesi. International Food Research Journal, 21(3), 1017-1023.

Parrado, J., Miramontes, E., Jover, M., Gutierrez, J.F. and de Teran, C. (2006). Preparation of a rice bran enzymatic extract with potential use as functional food. Food Chemistry, 98, 742-748. https:// doi.org/10.1016/j.foodchem.2005.07.016

Pegg, R. (2005). Lipid Oxidation Stability. In Wrolstad, R.E., Acree, T.E., Decker, E.A., Penner, M.H., Reid, D.S., Schwartz, S.J., Shoemaker, C.F., Smith, D.M. and Sporns, P. (Eds.) Handbook of Food Analytical Chemistry: Water, Proteins, Enzymes, Lipid and Carbohydrates. Canada: John Wiley and Sons Inc.

Pokorny, J. and Sakurai, H. (2002). Role of oxidized lipids in non-enzymatic browning reactions. International Congress Series, 1245, 373-374. https://doi.org/10.1016/S0531-5131(02)00920-2

Reineccius, G. (2006). Changes in Food Flavor due to Processing, In Flavor Chemistry and Technology. Boca Raton: Taylor and Francis Group.

Richardsa, A., Wijesunderaa, C. and Salisbury, P. (2005). Evaluation of oxidative stability of canola oils by headspace analysis. Journal of The American Oil Chemists' Society, 82, 869-874. https:// doi.org/10.1007/s11746-005-1157-3

Rohman, A., Che Man, Y.B., Ismail, A. and Hashim, P. (2011). Monitoring the oxidative stability of virgin coconut oil during oven test using chemical indexes and FTIR spectroscopy. International Food 
Research Journal, 18, 303-310.

Shahidi, F. and Zhong, Y. (2010). Lipid Oxidation:

Measurement Methods, Bailey's Industrial Oil and

Fat Products. New York: John Wiley and Sons Inc.

Srisawat, U., Panunto, W., Kaendee, N., Tanuchit, S., Itharat, A. and Lerdvuthisopon, N. (2010). Determination of phenolic compounds, flavonoids and antioxidant activities in water extracts of Thai red and white rice cultivars. Journal of the Med Ass of Thailand, 93(7), 83-91.

Tananuwong, K. and Tewaruth, W. (2010). Extraction and application of antioxidants from black glutinous rice. Food Science and Technology, 43, 476-481.

Thanonkaew, A., Benjakul, S., Visessanguan, W. and Decker, E.A. (2006). Development of yellow pigmentation in squid (Loligo peali) as a result of lipid oxidation. Journal of Agricultural and Food Chemistry, 54, 956-962. https://doi.org/10.1021/ jf052107h

Valantina, R.S. and Neelameagam, P. (2008). A study of rheological behavior and oxidative stability of rice bran and corn oil using FTIR spectra. International Journal of Pure and Applied Physics, 4, 77-86.

$\mathrm{Xu}, \mathrm{Z}$. and Godber, S.J. (1999). Purification and identification of components of $\gamma$-oryzanol in rice bran oil. Journal of Agricultural and Food Chemistry, 47(7), 2724-2728. https:// doi.org/10.1021/jf981175j

Zamora, R. and Hidalgo, F.J. (2011) The maillard reaction and lipid oxidation. Lipid Technology, 23 (3), 59-62. https://doi.org/10.1002/lite.201100094 